\title{
Richtlijn gebruik portfolio in de vervolgopleiding
}

\author{
J.O. Busari, L.G.J.M. Dirksen-de Tombe, E. Jippes
}

\section{Voorwoord}

Deze Richtlijn in het kader van het In VIVO-project is gebaseerd op literatuuronderzoek en op beperkt onderzoek in de praktijk. De Richtlijn is ontwikkeld in een samenwerking van de In VIVO kernteams van de Onderwijs- en Opleidingsregio's (OOR) Groningen, Rotterdam en Maastricht en namens de leden van de drie kernteams geschreven door dr. Jamiu Busari (voorzitter, Maastricht), drs. Liesbeth Dirksen-de Tombe (Rotterdam) en drs. Erik Jippes (Groningen).

\section{Status van de Richtlijn}

De Richtlijn heeft een adviserende status, en is enerzijds bedoeld als hulp bij het begeleiden en beoordelen van artsen in opleiding tot specialist (aios) door de opleider, en anderzijds voor het documenteren en sturen van de eigen opleiding door de aios. In het Kaderbesluit van het College Geneeskundige Specialismen (CGS) is het gebruik van het portfolio verplicht gesteld. ${ }^{1}$ Het is noodzakelijk op basis van verder onderzoek de Richtlijn te blijven ontwikkelen.

\section{Inleiding}

Deze Richtlijn wil een antwoord geven op de volgende vragen:

- Welke rol speelt het portfolio in de opleiding tot medisch specialist?

- Hoe gebruikt de aios het portfolio?

- Hoe gebruiken de opleider, de stagebegeleider, de supervisor en de mentor het portfolio?

\section{Doel van het portfolio}

Het CGS definieert in het Kaderbesluit van 2011 het portfolio als volgt:

\section{"Een verzameling van documenten waarin de verplichtingen voortvloeiende uit dit besluit en de specifieke besluiten worden bijgehouden, waaruit de voort- gang van de opleiding en de zelfreflectie van de aios blijken, met tenminste de documenten ten behoeve van de beoor- deling van de aios, de gehouden voor- drachten en referaten, de gepubliceerde artikelen, de gevolgde cursussen en de uitgevoerde verrichtingen."}

Uit deze definitie van het CGS valt op te maken dat het aios-portfolio zowel een ontwikkelings- als een beoordelingsdoel heeft. In deze Richtlijn richten wij ons op het portfolio als ontwikkelingsinstrument. Voor de beoordeling op basis van het portfolio verwijzen we de lezer naar de Richtlijn 'Interpretatie en gebruik van toetsresultaten in het portfolio' van Govaerts et al. ${ }^{2}$

\section{Inhoud van het portfolio}

Het portfolio bevat aan de ene kant stukken over de ontwikkeling van de aios vanaf de start tot en met de afronding van de opleiding $(\mathrm{CV}$, verslagen van introductie-, voortgangs- en beoordelingsgesprekken). En aan de andere kant bevat het portfolio 'bewijsmateriaal' waarmee de aios aantoont dat deze de gestelde (tussen)doelen heeft bereikt. Het portfolio dient volgens het Kaderbesluit tenminste de volgende delen te bevatten: 
- Het Individueel Opleidingsplan (IOP).

- Documentatie van minimaal de verplichte toetsingen van de competenties.

- Verslagen van de voortgangsgesprekken en beoordelingsgesprekken.

- Registratie van de door de aios uitgevoerde verplichte opleidingsactiviteiten.

- Eén of meerdere overdrachtsdocumenten.

Onder een overdrachtsdocument wordt verstaan het verslag dat is opgesteld door de opleider van de instelling waar de aios het betreffende onderdeel van de opleiding heeft afgerond en dat is gericht aan de opleider waar de aios zijn opleiding vervolgt, met als doel de continuïteit en voortgang van de aios tijdens de opleiding te waarborgen.

\section{Gebruik van het portfolio door de aios}

Het portfolio helpt de aios inzicht te krijgen in verworven competenties en nog te verwerven competenties. De aios is verantwoordelijk voor het bijhouden en vullen van het portfolio, met onder andere zijn* beoordelingen, de gehouden voordrachten en referaten, de gepubliceerde artikelen, de gevolgde cursussen en de uitgevoerde verrichtingen. Op die manier kan de aios zelf sturing geven aan zijn opleiding. Om dit te bereiken moet de aios leerdoelen formuleren in het IOP, bewijsmaterialen verzamelen, zichzelf beoordelen (zelfreflectie), de leerdoelen evalueren en opnieuw leerdoelen formuleren in het IOP. De leerdoelen worden bij voorkeur via de SMART-methode (Specifiek, Meetbaar, Acceptabel, Realistisch en Tijdsgebonden) geformuleerd.

Het onderwijsschema (Figuur 1) laat zien dat het portfolio centraal staat in de opleiding. Bij de start van de opleiding heeft de aios een kennismakingsgesprek met de opleider waarin afspraken worden gemaakt over de inhoud van de opleiding. De aios neemt de afspraken die daar gemaakt worden mee in zijn portfolio naar het introductiegesprek met de stagebegeleider van het te volgen opleidingsonderdeel. In dat gesprek worden afspraken gemaakt over de persoonlijke leerdoelen en de opleidingsdoelen (IOP) voor de komende periode, die worden vastgelegd in het portfolio. Tijdens het opleidingsonderdeel wordt het bewijsmateriaal vergaard in het portfolio wat dan weer gebruikt wordt als input voor het voortgangsgesprek en voor het opstellen van een (volgend) IOP.

\section{Reflectie}

Men veronderstelt dat dokters die regelmatig reflecteren op hun werkervaring en proberen te leren van de praktijk, hun patiënten beter van dienst zijn dan diegenen die dit niet doen. Reflectie is daarom van fundamenteel belang voor het praktijkleren en voor een leven lang leren. Het is te beschouwen als een cyclisch proces van zelfregulatie waarbij de aios terugkijkt op zijn acties, deze analyseert, nadenkt over alternatieven, deze uitprobeert in de praktijk, weer terugkijkt, enzovoorts. Het ontwikkelen van reflectieve vaardigheden is een manier om ervoor te zorgen dat men vragen blijft stellen ten aanzien van de waarde van bepaalde handelingen en aannames in het werkveld. Het alert zijn op het stellen van relevante vragen is een belangrijk onderdeel van het ontwikkelen van een professionele identiteit. De zelfevaluatie is één van de leidende activiteiten binnen de professionele opleiding en het portfolio kan worden ge-

* Er is voor de leesbaarheid gekozen om "hij” en "zijn” te gebruiken, op de plaatsen kan ook "zij” en "haar" gelezen worden. 


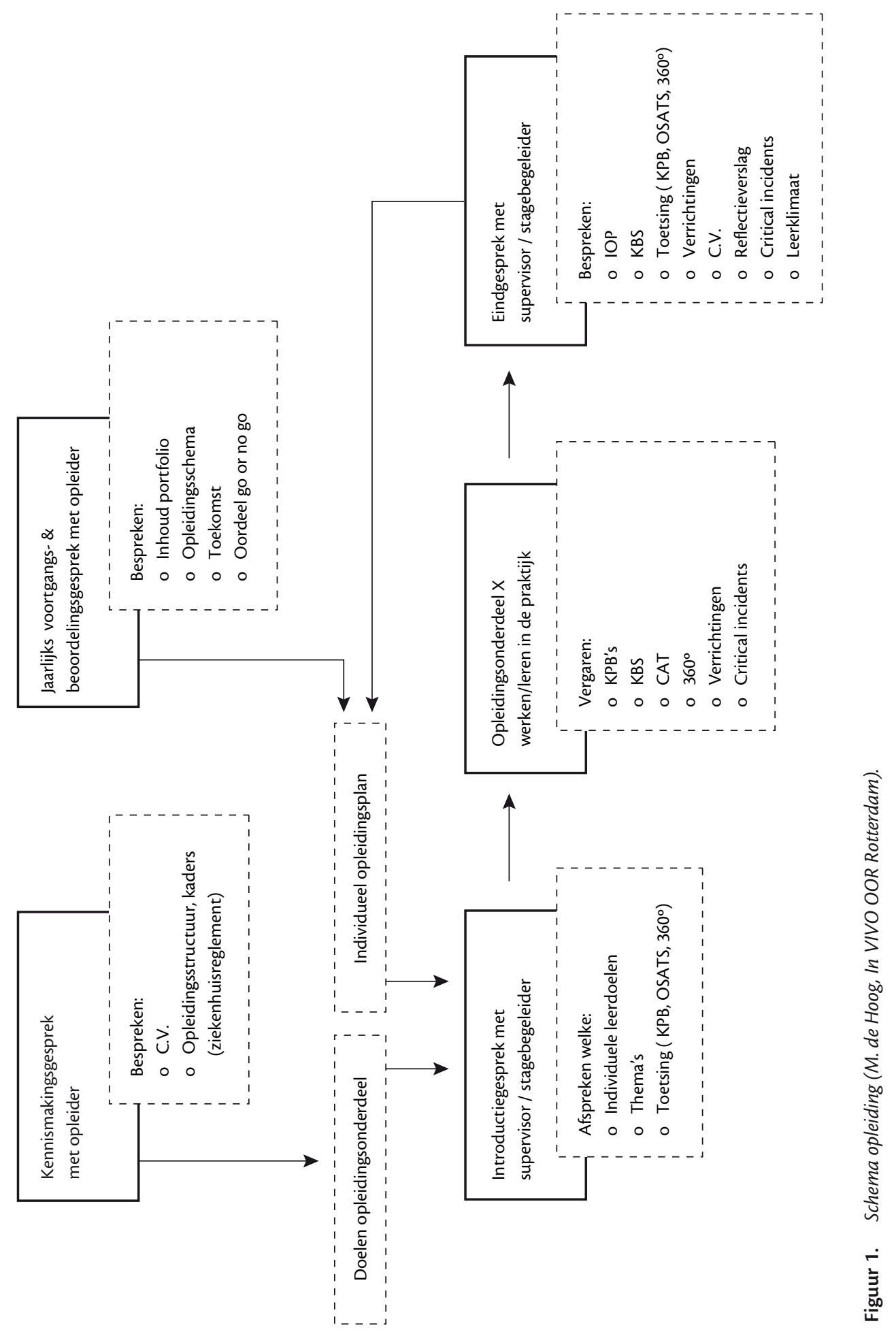


zien als het instrument bij uitstek voor zowel het begeleiden en beoordelen van het praktijkleren als voor reflectie. Een 'critical incident' bespreking is een manier om reflectie te stimuleren. In een reflectie op een critical incident moet beschreven worden wat de rol van de aios hierbij is en zijn verantwoordelijkheden als medische professional. Dit essay moet een waardevolle bijdrage leveren aan de professionele ontwikkeling van de aios (kennis en vaardigheden) en waar mogelijk een reflectie zijn van de stand van zaken van het huidige onderzoek en 'best practices'. Het kan de aios helpen bij het inzichtelijk maken van zijn professionele groei in de loop van het opleidingsprogramma. Criteria die gebruikt kunnen worden bij de beoordeling van een critical incident zijn:

- Rol en verantwoordelijkheden van de aios als medische professional.

- Bijdrage aan de eigen professionele ontwikkeling van de aios.

- Beschouwing van de verschillende competentiegebieden.

- Verband met research and best practices (waar mogelijk en nodig).

\section{Rollen van de klinische staf bij het portfolio}

\section{De opleider*}

Met het portfolio krijgt de opleider zicht op de competentieontwikkeling van de aios. De competentieontwikkeling wordt besproken tijdens de voortgangs- en geschiktheidsbeoordelingsgesprekken (Figuur 1). Volgens het Kaderbesluit CGS moet de opleider erop toezien dat de aios het portfolio bijhoudt, moet hij controleren of het voldoet aan de opleidingseisen, en moet hij verklaren dat het volledig en juist is. ${ }^{1}$

\section{De stagebegeleider}

De stage is in de nieuwe regelgeving veranderd in een opleidingsonderdeel. Een opleidingsonderdeel is een gedeelte van de opleiding in een medisch specialisme dat wordt gevolgd in een opleidingsinrichting en bij een opleider, en waarvan de inhoud, het leermiddel, de toetsing, de duur, de verplichte of facultatieve status, het bekwaamheidsniveau en eventueel plaats of patiëntenpopulatie zijn beschreven in het betreffende specifieke besluit of opleidingsplan. De stagebegeleider is diegene die verantwoordelijk is voor de opleiding van de aios op de werkplek. Dat kan soms de opleider zijn, maar in grotere opleidingsinstellingen is dat vaak een daartoe aangewezen stagebegeleider. De stagebegeleider voert de introductie-, tussen- en eindgesprekken van het opleidingsonderdeel met de aios.

\section{De supervisor}

De supervisor is de directe begeleider van de aios op de werkplek. De supervisor geeft de aios feedback op zijn handelen in de praktijk. Hij maakt hiervoor gebruik van de toetsinstrumenten zoals de KPB (Korte Praktijkbeoordeling) en de OSATS (Objective Structured Assessment of Technical Skills). Deze formulieren komen terecht in het portfolio van de aios. Cruciaal voor deze taak is kennis van het gebruik van het portfolio als een ontwikkelings- en beoordelingsinstrument. De taak van de supervisor is het waarborgen dat relevante informatie over de voortgang en prestaties ter beschikking wordt gesteld aan de opleider, vooral als deze prestaties aanleiding geven tot bezorgdheid. De supervisoren moeten toegang hebben tot de bekwaamverklaringen voor bepaalde verrichtingen, zodat ze

* Waar in deze Richtlijn wordt gesproken van opleider is steeds tevens plaatsvervangend opleider bedoeld. 
kunnen zien welke verrichtingen de aios zelfstandig (of onder een bepaalde mate van supervisie) mag uitvoeren. Tenslotte zijn de supervisoren (mede)verantwoordelijk voor het creëren van een goed opleidingsklimaat op de werkplek waar constructieve feedback aan de aios wordt gegeven en de supervisoren tijd moeten reserveren om de voorgaande activiteiten uit te voeren.

\section{De mentor}

Naast de opleider, de stagebegeleider en de supervisor wordt soms de rol van mentor onderscheiden. Dit is een vertrouwenspersoon die gedurende de gehele opleidingstijd de ontwikkeling op enige afstand volgt. De mentor is een ervaren en onafhankelijke supervisor of ouderejaars aios: hij kan helpen bij het opstellen van een IOP, een klankbord zijn, stimuleren tot zelfreflectie en adviseren over wat kan worden verbeterd in het portfolio. Eventuele drempels in de opleiding, het werk of in het persoonlijk leven kunnen vertrouwelijk besproken worden met de mentor.

\section{Gesprekken met de aios}

\section{Gespreksfrequentie en doelen van de gesprekken}

De formatieve evaluatiemomenten in het voortgangsgesprek zijn bedoeld om de aios te coachen en te begeleiden in het leertraject. De summatieve evaluatiemomenten zijn geschiktheidsbeoordelingen. In deze gesprekken wordt het portfolio gebruikt om een beslissing te nemen over de voortgang. Voor meer informatie over het summatief gebruik van het portfolio verwijzen we naar de Richtlijn 'Interpretatie en gebruik van toetsresultaten in het portfolio' ${ }^{2}$

In het eerste en tweede jaar vinden de voortgangsgesprekken driemaandelijks plaats, in het derde en vierde jaar halfjaarlijks en in het vijfde en zesde jaar jaarlijks. Aan het einde van ieder jaar vindt een geschiktheidsbeoordeling plaats, een 'go-no go' moment (zie Tabel 1). In alle gesprekken speelt het portfolio een centrale rol.

\section{Kennismakingsgesprek met de opleider}

Bij de start van de opleiding vindt een kennismakingsgesprek (veelal met de opleider) plaats. Het gesprek heeft drie doelen: kennismaken met de opleider, kennis nemen van de inhoud en van de toetsing in de opleiding en het maken van afspraken over de te behalen doelen voor de komende tijd.

In het gesprek komen de volgende punten aan de orde: het landelijke en regionale dan wel lokale opleidingsplan, het overzicht van de opleidingsonderdelen voor het eerste jaar (opleidingsschema), de planning van de voortgangs- en ge-

Tabel 1. Gespreksfrequentie volgens het Kaderbesluit CGS.

\begin{tabular}{cccc}
\hline Jaar van de opleiding & Introductiegesprek & $\begin{array}{c}\text { Voortgangsgesprek } \\
\text { (formatief) }\end{array}$ & $\begin{array}{c}\text { Geschiktheids- } \\
\text { beoordelingsgesprek } \\
\text { (summatief) }\end{array}$ \\
\hline 1 & 1 & 4 & 1 \\
2 & & 4 & 1 \\
3 & 2 & 1 \\
4 & 2 & 1 \\
5 & 1 & 1 \\
6 & 1 & 1 \\
\hline
\end{tabular}


schiktheidsbeoordelingsgesprekken, het CV van de aios en eventueel de sterkte/ zwakte analyse uit eerdere ervaringen, bijvoorbeeld uit het laatste jaar van de coschappen of de ervaring als assistent niet in opleiding tot specialist (anios).

Van de inhoud van de opleiding kan de aios tevoren kennis nemen door het bestuderen van het opleidingsplan. De aios kan op basis van het opleidingsschema bekijken of hij vanwege werkervaring voorafgaand aan de toelating tot de opleiding, misschien al beschikt over een deel van de gevraagde competenties. Aan de hand van de eerdere ervaringen kan door de aios en opleider afgesproken worden waaraan de aios de komende periode gaat werken. Er worden afspraken gemaakt over de verrichtingen die de aios kan doen en de mate van supervisie bij de verschillende activiteiten en verrichtingen. Van dit gesprek wordt een verslag gemaakt dat kan dienen als startdocument voor het volgende voortgangsgesprek met de opleider of voor het introductiegesprek met de stagebegeleider. Zie voor de wijze van voorbereiding op deze gesprekken deel 2, de Achtergronden bij deze Richtlijn.

\section{Introductiegesprek met de stagebegeleider*}

Voor aanvang van een opleidingsonderdeel wordt in een introductiegesprek besproken welke leerdoelen tijdens het opleidingsonderdeel gerealiseerd zullen moeten worden. De stagebegeleider geeft aan welke specifieke leerdoelen gekoppeld zijn aan het opleidingsonderdeel. De aios geeft persoonlijke leerdoelen aan en beschrijft in het IOP hoe de leerdoelen behaald en getoetst zullen worden. Zo nodig past de stagebegeleider deze aan en hij be- oordeelt of de leerdoelen met de SMARTmethode geformuleerd zijn. In het introductiegesprek met de stagebegeleider wordt het IOP concreet gemaakt. Vragen die aan bod komen tijdens dit gesprek zijn: Wat waren de leerdoelen uit het vorige opleidingsonderdeel? In hoeverre zijn deze bereikt? Wat waren de sterke en zwakke punten van de aios voor het komende opleidingsonderdeel? Welke leerdoelen heeft de aio zelf? Welke activiteiten en verrichtingen moeten op welke bekwaamheidsniveaus worden uitgevoerd? Hoe kan/gaat de aios deze doelen bereiken? Hoeveel KPB's moeten er worden afgenomen en waar worden deze afgenomen? Worden er nog andere toetsinstrumenten gebruikt tijdens het opleidingsonderdeel? En wanneer is het eerstkomende vervolggesprek met de stagebegeleider?

\section{Eindgesprek met de stagebegeleider}

Aan het eind van een opleidingsonderdeel wordt door de stagebegeleider een eindbeoordeling gegeven. De beoordeling wordt met de aios besproken en het verslag hiervan wordt in het portfolio opgenomen. Zoals in Figuur 1 te zien is wordt dit verslag gebruikt bij het voortgangsgesprek en bij het geschiktheidsbeoordelingsgesprek met de opleider.

\section{Voortgangsgesprek en geschiktheidsbe- oordelingsgesprek met de opleider}

In het eerste jaar moeten er vier voortgangsgesprekken plaatsvinden. In Box 1 staat beschreven hoe de aios en de opleider zich hierop kunnen voorbereiden. De voortgangsgesprekken dienen vooral om vast te stellen of de voortgang van de opleiding gaat zoals verwacht. De voortgangsgesprekken hebben primair een formatief (ontwik-

* In kleinere opleidingsziekenhuizen zijn er veelal geen afzonderlijke opleidingsonderdelen en stagebegeleiders. Indien er geen stagebegeleiders zijn, dan behoren deze taken tot de taken van de opleider. 
kelingsgericht) doel. Aan het eind van ieder jaar vindt er een geschiktheidsbeoordelingsgesprek tussen aios en opleider plaats. Dit gesprek verloopt op vergelijkbare wijze als het voortgangsgesprek. Het enige belangrijke verschil is dat de opleider in het gesprek een beslissing neemt over de voortgang van de opleiding. Indien een aios onvoldoende voortgang vertoont, wordt verwezen naar het Kaderbesluit. Er kan bijvoorbeeld een geïntensiveerd begeleidingstraject worden overwogen.

\section{De goede en minder goede aios}

\section{Begeleiden en beoordelen van een excellente aios}

Het landelijke en regionale opleidingsplan bevat de minimale bekwaamheidsniveaus die de aios in de loop van zijn opleiding moet halen. Het tempo waarin aios deze bekwaamheidsniveaus halen kan per individu verschillen. Dat is één van de uitgangspunten van competentiegericht opleiden. Het zou mogelijk moeten zijn dat 'snelle, excellente aios' een korting krijgen op hun opleiding, maar dat is op dit moment formeel nog niet mogelijk. De opleidingsduur die per opleiding in een specifiek besluit is vastgelegd is bepalend. Binnen de resterende tijd is het zaak om samen met de excellente aios een voldoende uitdagend programma samen te stellen. Verschillende opties zijn mogelijk zoals verdieping en verbreding. Verdieping kan op al bestaande opleidingsonderdelen, waarbij bijvoorbeeld gedacht kan worden aan het autoriseren van een

\section{Box 1. Handvat voor de voorbereiding op een voortgangsgesprek met behulp van het portfolio.}

\section{Voorbereiding door de aios}

Als voorbereiding op het voortgangsgesprek inventariseert de aios of hij alle documenten zoals afgesproken in het vorige gesprek heeft verzameld. Hiervoor kan hij terugkijken op het verslag van het introductie- of voorgaande gesprek.

De aios schrijft vervolgens voor zichzelf op wat hij de afgelopen tijd geleerd heeft. Dit terugkijken zonder oordelen is belangrijk omdat de aios eerst alles zo compleet mogelijk op een rij moet zetten. Wanneer de aios direct zou gaan interpreteren bestaat de kans dat het meest in het oog springende de overige ervaringen zal overschaduwen.

De volgende stap in het reflectieproces is de beoordeling van de verzamelde documenten. De aios leest de beoordelingen en vooral de narratieve feedback op de KPB's, OSATS en andere formulieren die hij verzameld heeft. Aan de hand hiervan stelt hij voor zichzelf een sterkte/zwakte analyse op.

De aios stelt zichzelf de volgende vragen: Wat gaat er goed? Wat vind ik moeilijk? Wat zou ik de volgende keer anders doen? Wat was de situatie? Waar speelde deze zich af? Wat was uw rol? Wat verwachtte de ander? Wat waren uw acties en waarom? De uitkomsten van de analyse zoals hierboven beschreven kunnen een onderbouwing vormen voor het door de aios ingevulde zelfbeoordelingsformulier. Het zelfbeoordelingsformulier heeft als hoofdpunten de zeven CanMEDS competenties met onder iedere competentie een aantal subcategorieën. De aios levert vervolgens het portfolio, inclusief het zelfbeoordelingsformulier, ruim op tijd voor het gesprek (minimaal een week) in bij de opleider.

\section{Voorbereiding door de opleider}

De opleider bestudeert het portfolio van de aios en vult ook het beoordelingsformulier in. Hij zorgt dat de aios dit formulier ruim op tijd voor het gesprek heeft (minimaal een week). Om wederzijdse beïnvloeding te voorkomen is het aan te bevelen om een derde, bijvoorbeeld iemand van het secretariaat, te vragen beide beoordelingsformulieren te verzamelen en gelijktijdig beide ingevulde formulieren naar de aios en opleider te sturen.

\section{Het gesprek zelf}

Bij de start van het gesprek maken aios en opleider samen een agenda met de te bespreken punten. Belangrijk is om in de tijdsplanning voldoende ruimte in te plannen voor het laatste onderdeel van het gesprek: de planning van de leerdoelen voor de komende periode. De overeenkomsten en verschillen tussen het oordeel van de aios en de opleider op het zelfbeoordelingsformulier kunnen hierbij de leidraad vormen voor het voortgangsgesprek. 
aios voor het doen van bepaalde ingrepen. Hiervoor is het instrument van de bekwaamverklaringen ontwikkeld. Zie voor de toepassingen van bekwaamverklaringen de betreffende Richtlijn van Lips et al. ${ }^{3}$ Deze ingrepen kan de aios dan zonder of onder beperkte supervisie uitvoeren. Een mogelijke verdieping zou ook in de supervisie/leidinggevende rol gezocht kunnen worden, door een aios superviserende taken te geven voor een afdeling.

Bij verbreding kan gedacht worden aan medisch inhoudelijke deelgebieden van het specialisme die nog niet in de opleiding aan bod zijn gekomen. Een verbreding zou echter ook in een niet-medisch inhoudelijke hoek gezocht kunnen worden, bijvoorbeeld het doen van wetenschappelijk onderzoek, of het zich bezighouden met kwaliteitszorg in medische afdelingen, met medische ethiek, enzovoort. In het IOP van de aios maken de opleider en aios afspraken over het individuele ontwikkelingspad van de aios. Voor de excellente aios bestaat dus, bovenop het minimaal vereiste niveau, de mogelijkheid van een 'individueel verrijkingsprogramma', als verdieping of verbreding.

\section{Begeleiden en beoordelen van een disfunctionerende aios}

Indien een aios niet naar verwachting functioneert kan naar aanleiding van een voortgangsgesprek, een jaarlijkse geschiktheidsbeoordeling of een eindbeoordeling besloten worden een geïntensiveerd begeleidingstraject te starten. Een dergelijk traject duurt minimaal drie maanden en maximaal zes maanden en wordt schriftelijk vastgelegd. De opleider wijst de aios op de geschillencommissie en brengt de Medische Specialisten Registratie Commissie (MSRC) op de hoogte. Voor het geïntensiveerd begeleidingstraject wordt het individuele opleidingsplan bijgesteld. Het opleidingsplan vermeldt de doelen van en de voorwaarden waaronder het traject plaatsvindt. Aios en opleider spreken af waar extra begeleiding en toetsing plaatsvindt. Het traject wordt afgesloten met een geschiktheidsbeoordeling. Een geïntensiveerd begeleidingstraject kan eenmaal plaatsvinden per opleiding - tenzij er bijzondere omstandigheden zijn - en kan leiden tot verlenging van de opleiding (voor details zie Kaderbesluit 1-1-2011 artikel B 22).

Indien de opleider twijfelt aan de geschiktheid van de aios voor het vak is het belangrijk meer informatie te verkrijgen om tot een afgewogen oordeel te komen. Een negatief oordeel ten aanzien van het functioneren dient ook dusdanig onderbouwd te zijn dat het stand houdt bij beroep. Wanneer men twijfel heeft over het functioneren van de aios, of wanneer men vindt dat de aios onvoldoende functioneert, dient dit zo spoedig mogelijk kenbaar gemaakt te worden aan betrokkene. Er wordt een plan gemaakt om vastgestelde lacunes te 'repareren' (zie het nieuwe Kaderbesluit voor de details).

\section{Het portfolio als beoordelings- instrument}

Beslissingen die mede op basis van het portfolio genomen worden, waaronder de jaarlijkse geschiktheidsbeoordeling voor de opleiding, vergen zowel een informatieve inhoud als een zorgvuldige weging van deze inhoud door de opleider. Twee benaderingen zijn mogelijk: een analytische en een globale. De analytische beoordeling weegt ieder onderdeel van het portfolio afzonderlijk, waarna een eindoordeel wordt samengesteld of soms wordt berekend. Dat heeft het voordeel van transparantie en verantwoording, vooral bij negatieve beslissingen. Het nadeel is de tijdsinvestering en ook het gegeven dat het hieruit voortvloeiende 'overall' beeld niet altijd goed past. De globale beoordeling geeft juist wel dit overall beeld en is 
soms zelfs betrouwbaarder. Het vergt echter goede bekendheid met de aios. Een goed globaal oordeel is niet mogelijk als de opleider die het oordeel moet vellen niet zelf goed vertrouwd is met de aios.

\section{Invoering van het portfoliogebruik in de opleiding}

Het gebruik van het portfolio door aios en opleider is verplicht gesteld in het Kaderbesluit. Enkele tips voor het effectief invoeren van het portfolio zijn:

1. De opleider moet de invoering van het portfolio in de afdeling goed voorbereiden:

a. in de eerste plaats is training van aios, opleider en eventueel stagebegeleider in het gebruik van het portfolio belangrijk,

b. training van aios zou gericht moeten zijn op het opstellen en evalueren van een IOP met de opleider,

c. training van opleiders zou het voeren van een voortgangsgesprek met de aios op basis van het portfolio moeten behandelen,

d. stagebegeleiders moeten getraind worden in het ondersteunen van de aios bij het opstellen en evalueren van het IOP,

e. de gehele opleidingsgroep en de aios moeten getraind worden in het gebruik van de toetsinstrumenten, en in het geven en ontvangen van constructieve en veilige feedback.

2. Bij de invoering van het portfolio is het ook belangrijk dat opleider en stagebegeleider het goede voorbeeld geven en het portfolio serieus nemen: a. dit betekent voor de opleider het daadwerkelijk bestuderen van het portfolio van de aios, voorafgaand aan het voortgangsgesprek, en het doornemen van (een gedeelte van) het portfolio tijdens het gesprek. Uiteraard houdt de aios het portfolio primair voor zichzelf bij.

3. Het verdient aanbeveling om de aios en supervisoren informatie te geven over het waarom en hoe van het portfolio.

4. Tot slot is het verstandig om bij de invoering van het portfolio enkele heldere afspraken te maken met de opleidingsgroep en met de aios over het gebruik van het portfolio. Deze afspraken bevatten de verschillende rollen en bijbehorende inzagerechten op de afdeling:

a. uitgangspunt is dat de aios eigenaar is van het portfolio. Voor de aios is het raadzaam om geen patiëntgegevens op te nemen en ten alle tijden het portfolio zorgvuldig te bewaren,

b. de opleider moet voorafgaand aan het voortgangsgesprek inzicht krijgen in het portfolio,

c. stagebegeleiders hebben veelal inzicht in het IOP, in ieder geval in het gedeelte van het IOP dat betrekking heeft op de stage,

d. de aios moet voor zichzelf afwegen of hij (diepe) persoonlijke reflecties (permanent) wil opnemen in het portfolio en wil bespreken met de opleider. Het wel bespreken met de opleider kan leiden tot meer diepgang in het gesprek. 